Discourse and Communication for Sustainable Education, vol. 3, pp. 121-134, 2012

\title{
EDUCATION FOR SUSTAINABLE DEVELOPMENT AT NOTRE DAME UNIVERSITY - LOUAIZE: ENVIRONMENTAL SCIENCE CURRICULUM - A PRE-PHASE TO THE RUCAS PROJECT ON EDUCATION FOR SUSTAINABLE DEVELOPMENT
}

\author{
Layla Khalaf-Kairouz \\ Notre Dame University - Louaize, Lebanon
}

\begin{abstract}
The Faculty of Natural and Applied Sciences at Notre Dame University - Louaize, conscious to the need of experts in the emerging field of sustainability and to the role that an educational institution plays for the service of the community, introduced into the university curricula a major in environmental science. This paper will present the programme's components, goals and implementation. The curriculum encompasses natural, social and managerial sciences, given the interdisciplinary nature of environmental science. Topical courses on water, soil and air pollution, environmental impact assessment and environmental ethics were designed, which integrate theory and practice. The graduates are prepared for managerial, communication and, most importantly, ethical competences to be able to implement best practices in environmental protection and play an active role in the community, especially the public, private, industrial and educational domains. At an inter-faculty level, the programme was successful in offering general education requirements courses on environment, sustainability and ethics, which helped in raising sustainability awareness among the students' population and strengthened the inter-faculty community relationships. To the present, the main focus of the programme was on education and preparation of graduates for the job market. Research, community outreach and campus sustainability practices need to be further addressed. Therefore, primary efforts should be exerted to improve the outcomes at these domains, especially that the university now joined the international educational programme: RUCAS - Tempus project, which emphasises development and improvements at all the institution sectors.
\end{abstract}

Key words: education for sustainability, Bachelor of Science in Environmental Science, students' competences, the Reorient University Curricula to Address Sustainability (RUCAS) Tempus project 


\section{Introduction}

Environmental science is by definition the study of the interactions between the biological and physical components of the environment and how humans are affecting the earth's natural systems (Miller, 2007). Being a part of the earth's support system and a major role player on the globe make it clear that sustainability and environmental concerns should become a major responsibility in our social and professional lives to be able to face the recent local and global environmental challenges. The natural potentially nonrenewable resources are being degraded through deforestation, desertification and wildlife habitat destruction. The mineral, energy and water resources are being poorly managed and depleted. The air, water and soils are being polluted through industrialisation, modern agricultural practices and toxic waste production. Climate change and ozone depletion are threatening globally the human population and the natural ecosystems. Most importantly, these changes are having severe impacts on our health as to life quality, morbidity and mortality.

In Lebanon, the local situation is not any better than on the global arena. Furthermore, in a country that suffered for more than thirty years from a civil war, the impacts on the environment were, unfortunately, well-marked on most of our environmental assets (Ministry of Environment, 2001). Solutions for a sustainable management of the natural resources and protection of the environment and human health necessitate professional intervention besides seeding the eco-citizen concept through awareness.

The Faculty of Natural and Applied Sciences (FNAS) at Notre Dame University Louaize (NDU), conscious to the need of experts in this emerging field and to the role that an educational institution plays for the service of the community, introduced into the curricula a study course "Environmental Science".

The programme effectively started in the academic year 1996/1997, as provided in the NDU - Louaize catalogue 1996-1997 (NDU, 1996). The originality of the programme at this year lied in the fact that it was new in Lebanon as it addressed more comprehensively environmental science rather than solely environmental health compared to the curricula offered at different Lebanese universities. The strength of the programme lies in the fact that our graduates have a comprehensive and well-balanced discipline-specific knowledge, have a sound multidisciplinary science foundation that allows them to pursue advanced studies in Lebanese universities or abroad and are ready for a wide job market range. To the present, the focus though is on developing the curricula and promoting the programme. Research, community outreach and campus sustainability practices need to be allocated further engagement.

In the year 2010, NDU joined the RUCAS - Tempus project "Reorient University Curricula to Address Sustainability". An interdisciplinary team from the different faculties was called upon by NDU research board to prepare for the implementation of the project policies at the university. In this respect, this paper will elaborate on the programme's components and its current implementation, and it will serve as a baseline for comparative assessment of the pre- and post-phases of the RUCAS - Tempus project on education for sustainable development (ESD) at NDU. This paper does not present an assessment of the programme as a whole. Though the number of the graduating students is still limited, our graduates are placed successfully at various environmental agencies. Within NDU, the programme showed a major success through the offered general education requirements (GER) courses, where multiple sections were opened each semester 
and the popularity of the environmental science courses encouraged the Sciences Department to continuously introduce new courses in this category.

\section{Programme's components}

Environmental science is by nature interdisciplinary, integrating nature, technology and culture (Cunningham, Cunningham, \& Woodworth Saigo, 2005). Therefore, the curriculum encompassed courses in:

- natural sciences: biology, chemistry, physics and geology;

- environmental science: water/soil/air pollution, environmental impact assessment, solid waste management and sustainable development, ecotourism, environmental health, environmental natural hazards, wastewater management, energy resources, environmental law and conservation of natural ecosystem;

- information technology sciences: computer science, geographic information systems and statistics;

- social and managerial sciences: ethics, law and economic and communication skills.

NDU adopts the credits system of education and is committed to the philosophy and standards of the American model of liberal arts education (NDU, 2012a). Therefore, the curricula are designed to offer a rich variety of general education study courses addressing social and cultural studies, philosophy and religion, citizenship and communication skills. The student is given freedom to choose from the set of GER courses as assigned by his/her major besides two free electives to their liking. The Bachelor of Science in Environmental Science requires the completion of 92 credits. Most of the courses of the major integrate theory and practice through laboratory and field work components. The students are equally encouraged to join training programmes in public and private sectors and non-governmental organisations (NGOs) (NDU, 2012b).

\section{Programme's mission}

The mission of the environmental science programme at NDU is to provide high quality education in environmental science through rigorous interdisciplinary approach that emphasises the study of interactions between environmental processes and human behaviour, in addition to environmental problem solving. This is in consistency of both mission statements of NDU and the FNAS. The FNAS commits itself to meet the needs of undergraduate students in the respective scientific disciplines and to improve their scientific education emphasising on theory, laboratory work and research. Through quality teaching, research and outreach activities the FNAS is keen to develop and spread scientific and technological knowledge. The FNAS guides students to be ethical, innovative and lifelong learners who will be leaders in their professions and communities (NDU, 2012c).

\section{Programme's objectives}

The environmental science programme at NDU endeavours to reach the following objectives: 
- provide students with theoretical knowledge about the relationship between environmental processes and human behaviour through an understanding of basic sciences, including biology, chemistry, geology, physics and statistics, as well as various topics of environmental science, including pollution, health, law, resources conservation and management and environmental impact and risk assessment;

- assist students in developing practical skills in field surveying and laboratory work, including analysis of environmental problems, data collection, analysis and modelling of human-environment systems;

- offer a multidisciplinary learning environment promoting high-level cognitive thinking skills, including critical thinking, problem-solving skills and integrative skills;

- train students to be effective communicators, with computer literacy and managerial/leadership skills;

- prepare graduates for a successful career at various sectors: industrial, governmental/private and educational;

- prepare environmental science graduates for advanced study and research;

- cultivate in students high moral and ethical standards and values as integrity, responsibility, compassion and community service.

\section{Programme students' learning outcomes/competences}

Competences are defined as a cluster of related knowledge, skills and attitudes that affect a major part of one's job (a role or responsibility) that correlates with performance on the job that can be measured against some accepted standards and can be improved via training and development (Parry, 1996, as cited in Centre for Disease Control [CDC], 2001). Competences express the four pillars of education for the 21 st century (learning to know, learning to do, learning to be and learning to live together) as stated by Delors (1996). Another pillar with a sustainable development dimension is added: learning to transform oneself and society (United Nations Educational, Scientific and Cultural Organisation [UNESCO], 2011) based on the fact that to achieve sustainable development, individual and collective actions are needed. The key competences as perceived by Brundiers, Wiek and Redman (2010) fit in three cluster categories 1) the strategic knowledge cluster encompasses the knowledge-based strategies that enable the transition from the current to a future sustainable state; 2) the practical knowledge cluster covers the implementation competencies that can bridge knowledge and action necessary for the transition towards a sustainable development; 3 ) the collaborative cluster is teambased and fundamental for developing collaboration with the various stakeholders in academia, decision-making agencies and civil society. Success in finding solutions for environmental problems lies in a sense of a strong bond with the people and the environment, which in the words of Brundiers et al. (2010), referring to previous researchers, needs engaging the heart along with the head and the hands. Mochizuki and Fadeeva (2010) point out that the institutions of higher education along with their stakeholders are developing an increasing interest in competence-based approaches in education, which can be the key to educational as well as societal changes towards sustainability. 
Competences reveal what the students should know and do after completion of the learning process. Therefore, competences should be subject-specific and generic in nature. The subject-specific competences are the basis for the professional development. The generic competences, on the other hand, are common to all disciplines and address abilities that can be further acquired through experience and training (CDC, 2001; Public Health Agency of Canada [PHAC], 2008). Accordingly, the competences in the environmental science programme at NDU are categorised as follows:

\section{subject-specific competences:}

key concepts about the environment through creative interdisciplinary approach: knowledge of basic concepts in biology, ecology, geology, hydrogeology, physics, chemistry, geographic information systems and statistics;

the ecological systems and relationships between environmental processes and human behaviour, as well as local, regional and global perspectives of environmental problems and their solutions;

sub-fields of environmental sciences, including environmental pollution, environmental impact assessment, sustainability, resources conservation and management, environmental health and geo-environmental hazards/risk assessment;

\section{analytical/research competences/skills:}

strong analytical ability with an understanding of theoretical and applied knowledge; research skills (desk and field): analysis of environmental problems, assessment of environmental components, research plan;

field analysis: field surveying, data collection, modelling of human environment systems; laboratory analytical know-how, compliance with international standards;

problem-solving skills to be able to propose sustainable solutions aiming at pollution prevention, environmental protection and natural resources conservation;

\section{managerial competences:}

demonstration of leadership skills and ability for collaboration in team-based projects, given the multidisciplinary nature of environmental science;

design of environmental assessment studies based on extensive research, field observation, data collection/analysis, monitoring, find appropriate integrated solutions, execution with a good time management;

data processing and representations and records compilation;

assessment of the effectiveness of the implemented procedures on the ecosystem and human health;

\section{communication skills:}

computer skills, good use of technology;

appropriate reading and writing capabilities;

ability to converse using appropriate scientific terminology;

scientific advice to the policy and decision makers;

data dissemination;

public speaking: awareness campaigns, education, training to be able to involve the community in the implementation;

good listening to the public concerns; 


\section{ethical competences:}

development and demonstration of values such as integrity, responsibility, compassion and service;

contribution to the protection and conservation of natural systems from any aspect of environmental degradation as pollution, disintegration of ecological functions and resources depletion;

application of solutions that combine ecological, economical, social and ethical considerations, while respecting the local culture and values of the concerned communities; motivation and services to the local community by initiating and participating in NGOs and spreading awareness on environmental issues;

respect of the others' cultures;

self-commitment to the sustainability principles in one's own actions;

active role in the community by being a responsible citizen: ecocitizen by excellence.

\section{Programme's implementation: Teaching/research/outreach}

\section{Teaching: Major courses and GER courses}

The environmental science curriculum was continuously reviewed to fine-tune with the NDU requirements on the one hand and with the government educational regulations on the other hand. The teaching/learning materials were updated to reflect the latest scientific understanding of sustainability and to keep pace with the dynamism and scientific advancement of this emerging science. The focus besides content was also on the teaching methods. Information technology and well-equipped laboratories are major pillars in the teaching process.

The major courses alongside with the theoretical part include a laboratory component. Field work and trips are organised to combine theory with practice. Field visits to nature reserves, research centres and private or public agencies are planned to provide hands-on experiences on the management of different environmental industries in the country, which gives a clear understanding of the realities of sustainable management with its implementation successes or difficulties. Experts, government and private officials are invited to introduce innovative research in the field and to convey their own experiences.

Capstone courses such as, for instance, "Environmental Impact Assessment" are based on a field application. The senior projects, which are a major output of the students are research-oriented on environmental topics in the country. Numerous projects were presented and published at local and international conferences.

At an inter-faculty level, the programme was successful in offering GER courses on environment, sustainability, society, ethics and sustainable development. These courses are offered each semester for more than two hundred students from all the different faculties (Humanities, Arts and Engineering). This helped in raising awareness on sustainability among the highly heterogeneous students' population. The objectives of the courses are for students to learn about environmental protection, develop a sense of belonging and appreciation for nature, be aware of daily practices and habits and become conscious about health protection. They are to apply the principles learned in class in everyday life. Van der Pluijm (2006) has drawn the attention to the fact that this category of courses provides the students with an early interdisciplinary knowledge that can help 
them decide on a major and plan for their future career. This was witnessed, especially by some civil engineering students that got specialised in disciplines related to sustainability issues and protection from environmental hazards as earthquakes engineering, mass wasting prevention and renewable energies, after they were introduced to these topics and their relevance to the country.

The students' projects targeted discovering the link between their major and environmental science. They are to integrate their discipline specific skills to promote the concepts of sustainability. Therefore, the students are to invest their know-how in service of environmental issues. The interdisciplinary nature of the themes tackled strengthened the inter-faculty community relationships as public presentations and poster sessions were organised at the university level, which also enlivened the campus life, created strong cooperation among the faculty members and allowed for a wider project exposure to students' population, faculty and staff.

Among some examples of students' works are posters for an antismoking campaign on campus. The posters provide Arabic proverbs having suggestive meanings or lexical plays to insinuate the smoking dangers (Figure 1). The administration financed the printing of the posters, and they were posted all over the campus. Other projects included remodelling old clothes and furs to trendy designs, redesigning the classrooms to a friendlier environment, designing a website for the environmental science major.

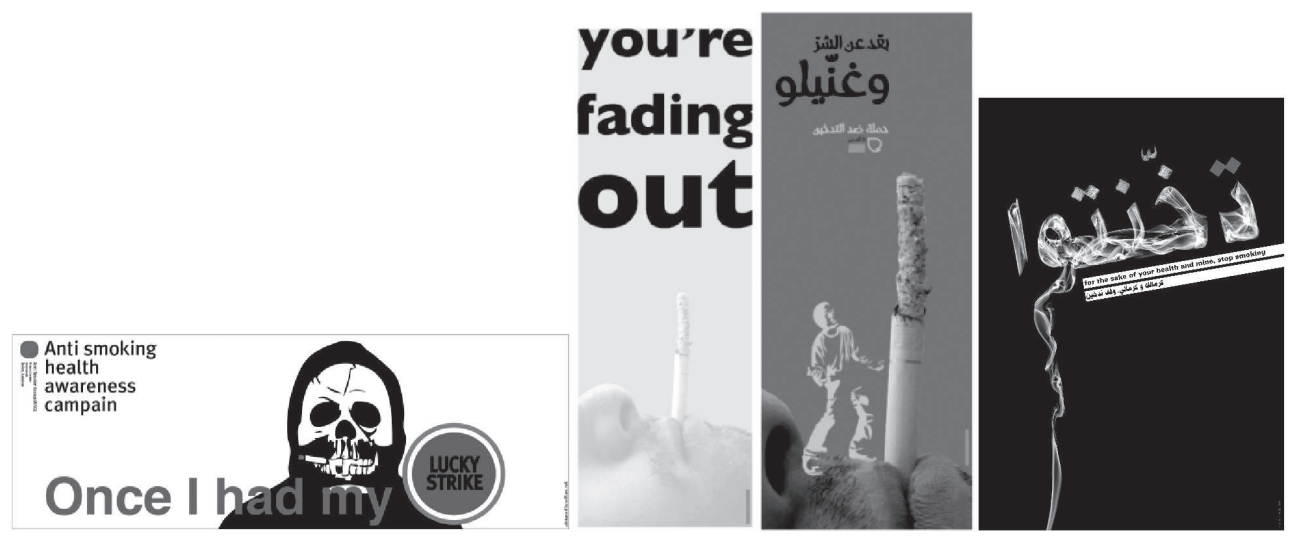

Figure 1. Posters for an anti-smoking campaign on campus, prepared by Graphic design students

The Faculty of Sciences offers also service courses to the other faculties among which is a course on physical geology for the civil engineering students. Presently, NDU joined the RUCAS - Tempus project, whereby sustainability concepts are to be infused within the course materials. A questionnaire elaborated by the RUCAS - Tempus project was distributed at the beginning of the course to assess the students' knowledge, understanding and behaviour regarding sustainability, economic consumption, good citizenship in a democratic society, living together in a multicultural community and importance of ESD. The students' sample consisted of 40 students. The results showed that a high percentage of students perceive the environmental awareness and its relationship to sustainable future as 'low', though they value environmental conservation. Also, a high percentage does not perceive the importance of production and consumption according to the sufficiency economy principle (Figure 2). Good citizenship, democracy, tolerance 
to others are respected. The importance of ESD is regarded as essential (Figure 3). Based upon these survey results, the need to infuse sustainability concepts also into the core courses is important, and the students realise the role of education in this respect. Accordingly, the projects in the course were oriented towards sustainability issues related to geological concerns of relevance to civil engineering. This pilot study will be complemented by another survey at the end of the course for post-assessment.

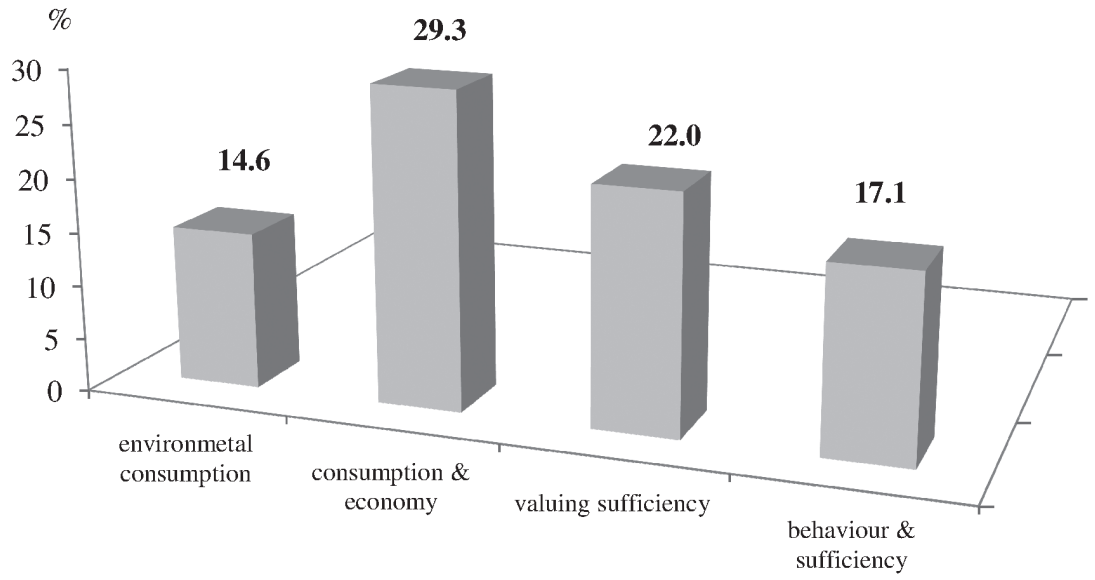

Figure 2. Percentages of students perceiving the importance of sufficiency economy principle and consumption as low.

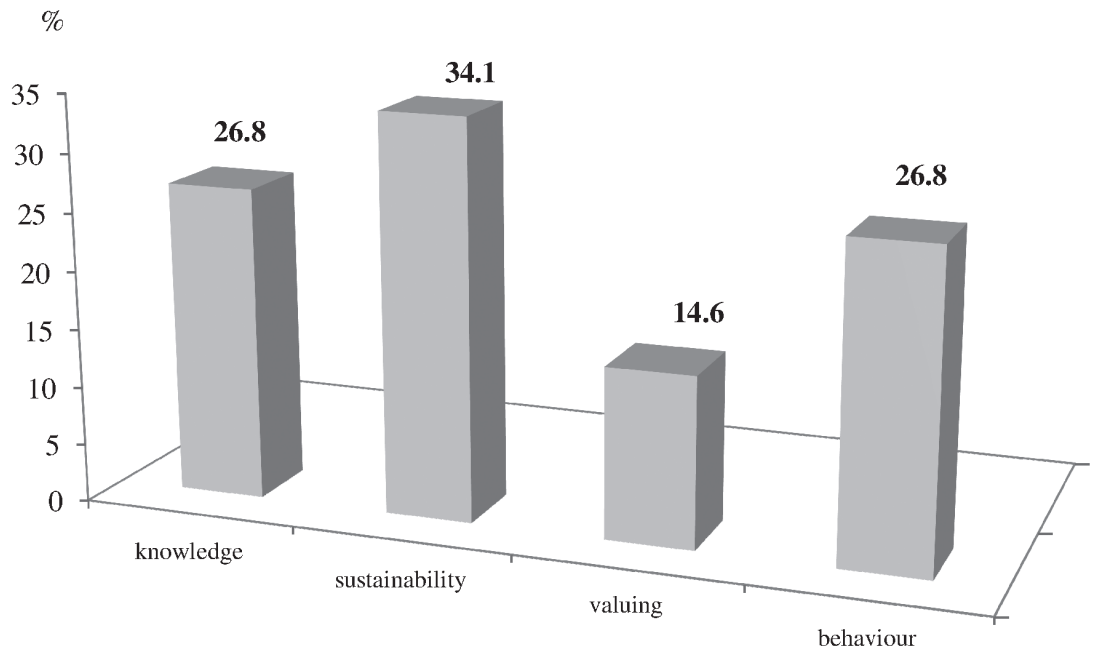

Figure 3. Percentages of students perceiving the environmental awareness and its relationship to sustainable future as low.

\section{Research}

The research conducted is mainly on water resources, environmental pollution and its impact on health and geoenvironmental hazards (Moarkech \& Khalaf-Kairouz, 2007; 
Khalaf-Kairouz \& Shaban, 2008). A major current project is on air pollution. The research is conceived to generate data on the quality of the air in the neighbourhood of NDU campus, where a major fuel-fired power plant is located. A statistical analysis on the respiratory health of children in the area and a geographical information system study to spot the most representative sampling spots preceded the sampling phases. An interuniversity collaboration is initiated for a wider areal coverage. Research projects on pollution that is clearly perceived as having an impact on health is convincing to the local community, and it paves the way to its involvement especially in terms of support and funding. The long-term goal of the research is to establish along with other universities in the country a national air quality research unit to continuously monitor and disseminate information about the air pollution status. The resulting research findings will help the decision making in improved resources conservation, better land-use planning and health protection as they are relying on evidence-based data.

In order to address the local status of global environmental issues, the Department of Sciences at the FNAS organised a conference on climate change in Lebanon in the year of 2010. Lebanese scholars and experts in this field at various sectors were invited: water, health, forestry, media and NGOs (NDU, 2010).

Further, the FNAS hosted the 18th international science meeting of the Lebanese Association for the Advancement of Sciences (LAAS) on March 22-24, 2012. The meeting included a major track on environmental issues (NDU, 2012d).

\section{Outreach}

The outreach activities comprised development of public awareness. Public presentations and discussions were held for local communities and NGOs. These included reflections on quality of life, preciousness of nature, environmental conservation, ethics and sustainable development in relation to the local culture. Matsuura (2009) emphasises on the importance of traditional values and knowledge of the indigenous people as bases for achieving sustainability. Breidlid (2009), based on the African experience, states that local knowledge is important for the people's self-esteem, it can contribute fundamentally to the education for sustainability in the developing countries in comparison to the western countries where the focus is on instructing the society to deviate from consumerism.

Schools were visited to elucidate to students the importance of an unpolluted environment and to instil in them at young age the eco-citizen culture. Schools were encouraged to create the so-called green clubs. Secondary schools were equally visited to promote the major of environmental science of NDU, brochures were distributed and clarifications about the course of studies were communicated.

Schoolchildren were invited to the campus of NDU to attend environmental exhibitions and get introduced to the facilities of NDU in order to attract them towards higher education for sustainability. Community outreach was also mediated through our students who attended the GER courses in sustainability. We can take pride that some students established environmental clubs in their districts, held lectures based on the course materials they acquired in class and communicated environmental knowledge to their clubs or scouts aided by audio-visuals borrowed from the university. They organised social events as trips to nature reserves. They aimed at raising awareness through an educated community, not only based on mere enthusiasm. 


\section{Discussion}

The programme of environmental science at NDU is designed meticulously to equip the students with a solid background to become successful professionals. Therefore, our graduates can be recruited as consultants, environmental officers, academicians and researchers in the following domains:

- public agencies: ministries of environment, water resources and electricity, tourism, urban planning and municipalities;

- industrial sector: water and food industries, waste management, wastewater treatment, pollution remediation and environmental auditing;

- engineering companies: environmental impact assessment, remediation techniques, protection from environmental hazards, mining and energy;

- environmental and health institutions: human environmental health and safety;

- wildlife protection associations: nature reserves, forests, wildlife management, recreational parks and ecotourism;

- educational and research institutes: research centres and schools.

NDU offers a teaching diploma in sciences as currently the environmental science discipline is implemented in secondary school education programmes.

In fact, though the number of our graduates is still small, they are successfully pursuing careers in major Lebanese or foreign environmental agencies, in engineering firms, in the Ministry of Environment and in schools, which is reported trough the alumni communications.

This ample range of working sectors makes it imperative that the graduates possess wide-ranging skills and qualities, which define their proficiency at the work place. The role of education is to enhance the development of students' competences which assure a successful professional career. Underwood (2008) also stressed that institutions are to prepare well the students for employment and citizenship in a world defined by environmental challenges. Therefore, the competences targeted by the programme ranged from subject-specific and analytical competences to management and communication skills to ethical competences. The competences and objectives of the programme are equally in line with the five pillars of UNESCO for education in sustainable development and cover the essential characteristics of ESD as defined by UNESCO (2005).

The mission and objectives of the programme are compatible with the Bologna Process (the Rectors' Conference of Finnish Universities of Applied Sciences [ARENE], 2007) requiring that education prepares for employability and citizenship. The social dimension is met by the FNAS mission of lifelong and student-centred learning, research and innovation.

Interdisciplinary integrated sustainability curriculum is proven very successful with respect to combining environmental, social, technical and economic aspects (Bacon, Mulvaney, Ball, DuPuis, Gliessman, Lipschutz, \& Shakouri, 2010). Van der Pluijm (2006) described the experience of the University of Michigan in introducing the global change curriculum and a minor as very successful due to the interdisciplinary nature of the included courses, which captures students' interests. Copeland (2009) pointed out that the environmental science programmes are proliferating in American universities; the number of students enrolled is equally growing as more and diversified career opportunities are available. Therefore, the campuses are working on their green images on and off-campus in terms of research, ecological restoration and environmental respon- 
sibility to the surrounding community and solutions development to pressing environmental challenges. Scores from several categories, including course offerings, environmental practices and policies, are compiled. Some institutions take on projects outside their campus and make strategic long-term plans that render the campus virtually having a carbon-neutral footprint (Underwood, 2008). Comparatively, this makes NDU and the FNAS specifically successful in terms of curricula and courses development. Research, community outreach and campus sustainability practices, on the other hand, should be further addressed. Students' involvement can be more active and engaging through service learning projects to the community. This fosters the students' ethical and social responsibilities and reveals to them the relevance of technology for the service of society (Chen, Vanasupa, London, \& Savage, 2006). Students' output at NDU is revealed in the senior projects of the students majoring in environmental science. These tackled various topics on local environmental concerns. With regard to students' opportunities, they are to the present limited to timid shares in research assistantship. The social life on campus gave the chance for a green club to be founded, which, in fact, had an intermittent output totally dependent on students' engagement. On the other hand, the students with different backgrounds who have registered in the GER courses showed good commitment and enthusiasm to projects related to sustainability as assigned by their registered courses.

The administration support to the programme has been full at the level of the faculty deanship, especially that the dean carries on the responsibility of convincing the administration of the university to introduce the programme into the curricula. In this respect, the higher administrative body, in turn, showed full support. Kritzek, Newport, White and Townsend (2011) allocate a major importance to 'the visionary campus leader' in the phases of evolution of sustainability initiatives on campus. The leader with a clear understanding of the principles of sustainability will executively give priority to sustainability in the university goals and strategic plans. Hopkinson \& James (2010), while illustrating the case of the University of Bradford in embedding ESD into the sciences curricula, referred to the importance of having the professionals and accreditations bodies perceiving seriously the importance of education in sustainable development.

The environmental research at NDU is being equally supported at both the financial level and with respect to upgrading the science laboratories and purchasing equipment specific for environmental research.

In the year 2010, NDU joined the international education programme: RUCAS Tempus (Reorient University Curricula to Address Sustainability). The project emphasises development and improvement at the following institutional sectors: curriculum, research and scholarships, operations, faculty and staff development and rewards, outreach and service, students' opportunities and administration mission and planning (University Leaders for a Sustainable Future, 2009). The dimensions discussed above represent the FNAS. The discussion did not include the achievements regarding sustainability education in the other six faculties of the university, which is beyond the scope of this paper. Therefore, the sustainability accomplishments of the FNAS, though they reflect to some extent those of the institution, do not alone represent the university as a whole. In this respect and from the perspective of the FNAS in terms of the curriculum, a major step has been achieved. As to research and scholarships, outreach and service and students' opportunities dimensions, these can be improved by the university administration support. Major efforts should be exerted at the level of planning, faculty and staff develop- 
ment and rewards. Kritzek et al. (2011) recommend this approach as it lifts the spirit of the organisation and improves its execution. Greening the campus with respect to the campus operations and practices also needs more executive procedures. These domains can become implemented solely by a decision at the university administration level.

\section{Conclusion}

The programme of environmental science at NDU offered by the FNAS prepares graduates for a successful future career, trains them to acquire skills at the personal, managerial and information technology levels with an emphasis on ethics and values. The programme provides them with a sound foundation in the natural and socioeconomic sciences with an application to solving environmental problems.

It allows for concentration flexibility as the students can choose elective courses from different disciplines, enabling to build concentrations within the major or at the interdepartmental level. Hands-on experience is gained from laboratory work, research projects, field trips and practical experience is acquired from training in environmental organisations and volunteer extracurricular activities with NGOs. The environmental science graduate is able to implement best practices in environmental protection and play an active role in the community. Our graduates have been placed effectively in varied environmental agencies. GER courses served at raising environmental awareness among the non-major students' population. Sustainability is equally addressed in the service courses.

To the present, the main focus of the programme was on education and preparation of the graduates for post-graduate studies and the job market. After that, NDU joined the RUCAS - Tempus programme; it committed itself to the embodiment of the sustainability at many levels. Key achievements have been already accomplished in curricula development and teaching. Research, outreach and student opportunities need to be further addressed. Major efforts are to be exerted at the level of campus practices, faculty and staff development and planning. At the academic level, the university has achieved a major step. This success can be sustained though by a further engaged campuscommunity and planning in order to render the education for sustainability sustainable.

\section{Acknowledgement}

This work has been developed within the framework of the RUCAS (Reorient University Curricula to Address Sustainability) project that has been funded from the European Commission (European Commission, TEMPUS - No. 511118-2010-GR-JPCR). The content of the paper reflects the views of the author, and the Commission cannot be held responsible for any use which may be made of the information contained therein.

\section{References:}

ARENE (The Rectors' Conference of Finnish Universities of Applied Sciences). (2007). The Bologna process and Finnish universities of applied sciences. Retrieved March 11, 2012, from http://www.ncp.fi/ects/materiaali/The Bologna Process and Finnish Universities of Applied Sciences 20012007.pdf 
Bacon, M., Mulvaney, D., Ball, T., DuPuis, M., Gliessman, R., Lipschutz R., \& Shakouri, A. (2010). The creation of an integrated sustainability curriculum and student praxis projects. International Journal of Sustainability in Higher Education, 12(2), 193208.

Breidlid, A. (2009). Culture, indigenous knowledge systems and sustainable development: A critical view of education in an African context. International Journal of Educational Development, 29(2), 140-149.

Brundiers, K., Wiek, A., \& Redman, C. L. (2010). Real-world learning opportunities in sustainability: From classroom into the real-world. International Journal of Sustainability in Higher Education, 11(4), 308-25.

CDC (Center for Disease Control). (2001). Environmental health competency project: Recommendations for core competencies for local environmental health practitioners. Retrieved March 11, 2012, from http:/www.cdc.gov/nceh/ehs/Corecomp/ Core_Competencies_EH_Practice.pdf

Chen, K. Vanasupa, L., London, B., \& Savage, R. (2006). Infusing the materials engineering curriculum with sustainability principles. Retrieved March 12, 2012, from http://search.asee.org/search/fetch? url=file $\% 3 \mathrm{~A} \% 2 \mathrm{~F} \% 2 \mathrm{Flocalhost} \% 2 \mathrm{FE} \% 3$ A $\% 2$ Fsearch $\% 2$ Fconference $\% 2 F 12 \% 2 F 2006$ Full378.pdf\&index=conference papers\&space $=129746797203605791716676178 \&$ type $=$ application $\% 2 F p d f \&$ charset $=$

Copeland, B. (2009). 10 of the best college environmental programs in the U.S. Retrieved January 30, 2012, from http://www.treehugger.com/culture/10-of-the-best-collegeenvironmental-programs-in-the-us.html

Cunningham, W., Cunningham, M. A., \& Woodworth Saigo, B. (2005). Environmental science, a global concern (8th edition). New York: McGraw-Hill.

Delors, J. (1996). Learning: The treasure within. Report to UNESCO of the International Commission on education for the 21st century. Retrieved May 1, 2012, from http://www.unesco.org/delors/delors_e.pdf

Hopkinson, P., \& James, P. (2010). Practical pedagogy for embedding ESD in science, technology, engineering and mathematics curricula. International Journal of Sustainability in Higher Education, 11(4), 365-379.

Khalaf-Kairouz, L., \& Shaban, A. (2008). Criteria and indicators of hydrological drought in Lebanon, 2008. Algerian Journal of Technology, 2, 875-889.

Kritzek, K., Newport, D., White, J., \& Townsend, A. (2011). Higher education sustainability imperative: How to practically respond? International Journal of Sustainability in Higher Education, 13(1), 19-33.

Matsuura, K. (2009). Training guideline on incorporating education for sustainable development (ESD) into the curriculum. Retrieved March 30, 2012, from http://www.ibe.unesco.org/fileadmin/user_upload/COPs/News_documents/2009/ 0905Bangkok/ESD_training_guidelines_-3.pdf

Miller, G. T. (2007). Living in the environment (15th edition). Canada: Thomson Brooks/ Cole.

Ministry of Environment. (2001). State of the environment report. Retrieved March 30, 2012, from http:/www.moe.gov.lb/publications.aspx

Moarkech, K., \& Khalaf-Kairouz, L. (2007). Vulnerability of El-Kabir River Basin, Akkar, to geo-environmental impacts using GIS techniques. L'ACQUA, Associazione Idrotecnica Italiana, 5, 39-44. 
Mochizuki, Y., \& Fadeeva, Z. (2010). Competences for sustainable development and sustainability, significance and challenges for ESD. International Journal of Sustainability in Higher Education, 11(4), 391-403.

NDU (Notre Dame University - Louaize). (1996). Notre Dame University - Louaize Catalogue 1996-1997. Lebanon, Zouk Mosbeh: NDU-Louaize press.

NDU (Notre Dame University - Louaize). (2010). NDU past conferences. Conference entitled: Impact of climate change on Lebanon. Retrieved March 30, 2012, from http://www.ndu.edu.lb/newsandevents/current/fnas_conf.htm

NDU (Notre Dame University - Louaize). (2012a). Identity, vision, mission and values. Retrieved March 30, 2012, from http://www.ndu.edu.lb/About/Identity.htm

NDU (Notre Dame University - Louaize). (2012b). The degree of Bachelor of Science in environmental science. Retrieved March 30, 2012, from http://www.ndu.edu.lb/ academics/fnas/ds/enc_science.htm

NDU (Notre Dame University - Louaize). (2012c). Faculty of Natural and Applied Sciences, mission, vision and values. Retrieved March 30, 2012, from http://electra.ndu.edu.lb/academics/fnas/mvv.htm

NDU (Notre Dame University - Louaize). (2012d). 18th international science meeting of the Lebanese Association for the Advancement of Science. Retrieved March 18, 2012, from http://www.ndu.edu.lb/laas18/files/LAAS_program.pdf

PHAC (Public Health Agency of Canada). (2008). Core competences for public health in Canada. Retrieved March 1, 2012, from http://www.phac-aspc.gc.ca/php-psp/ ccph-cesp/pdfs/cc-manual-eng090407.pdf

Underwood, K. (2008). Green college rankings now available from the Princeton review. Retrieved March 30, 2012, from http:/www.treehugger.com/corporate-responsibility/ green-college-rankings-now-available-from-the-princeton-review.html

UNESCO (United Nations Educational, Scientific and Cultural Organisation). (2005). United Nations Decade of Education for Sustainable Development (2005-2014): International implementation scheme. Retrieved May 1, 2012, from http://unesdoc. unesco.org/images/0014/001486/148654e.pdf

UNESCO (United Nations Educational, Scientific and Cultural Organisation). (2011). Five pillars of learning. Retrieved May 1, 2012, from http://www.unesco.org/new/ en/education/themes/leading-the-international-agenda/education-for-sustainabledevelopment/education-for-sustainable-development/five-pillars-of-learning/

University Leaders for a Sustainable Future. (2009). Sustainability assessment questionnaire (SAQ) for colleges and universities. Retrieved March 1, 2012, from http://www.ulsf.org/programs_saq.html

Van der Pluijm, B. (2006). The global change curriculum and minor at the University of Michigan. Journal of Geoscience Education, 54(3), 249-254.

\section{Correspondence:}

Layla Khalaf Kairouz, PhD, Associate Professor in Environmental Geology, Notre Dame University - Louaize, P.O. Box 72, Zouk Mikayel, Lebanon. Email: lkhalaf@ndu.edu.lb 